\title{
Palestinian schoolscapes in Israel
}

\author{
Muhammad H. Amara
}

\author{
Correspondence: muhamara2000@ \\ yahoo.com \\ Beit Berl College, Ma'ale Iron, Zalafa \\ Village, P.O.BOX 312, $3092000 \mathrm{Kfar}$ \\ Saba, Israel
}

\begin{abstract}
The linguistic repertoire of Palestinian citizens in Israel is complex and diverse. Arabic is the language of personal, cultural, and national identity. Hebrew is important for social mobility, higher education, and shared citizenship. English, as a global language, is a window to the wider world (Amara, Policy and teaching English to Palestinian students in Israel: An ecological perspective to language education policies, 2014). As to language education, Arabic is the language of instruction in Palestinian schools. Hebrew is studied as a second language by all the Palestinian students from the second grade on, or even earlier. English is studied as a foreign language from the third grade on, and in many schools even earlier (Amara, Policy and teaching English to Palestinian students in Israel: An ecological perspective to language education policies, 2014; Hebraization in the Palestinian language landscape in Israel, 2015). This study investigates the reflection of the three languages studied in the Palestinian schoolscapes. More specifically, the schoolscapes in six Palestinian high schools located in three towns in the Little Triangle in Israel are studied. The distribution of the languages in the schoolscapes was examined by exploring the functions of signs, distinguishing between informative and symbolic content, and determining the authorship of signs (topdown vs. bottom-up). Altogether 1216 photographs of signs were taken and analyzed. In addition, the 'tourist guide technique', developed by Szabó (Journal of Applied Language Studies 9:23-51 2015), was used. The findings reveal that Arabic, Hebrew, and English are used in the schoolscapes of the Palestinian schools in Israel. Arabic is the most ubiquitous language, and Hebrew is also present. While there is evidence of English, its use lags far behind that of the two other languages. The schoolscapes are largely monolingual (mainly Arabic) or bilingual (Arabic-Hebrew). Trilingual signs almost do not exist. Though Palestinian students are trilingual since they learn three languages at school, multilingualism is not truly reflected in their schoolscapes.
\end{abstract}

Keywords: Schoolscape, Palestinian schools, Arabic, Hebrew, English, Israel

\section{Introduction}

Over the last two decades, the subject of linguistic landscape has become a dynamic field of research. It has become far more prominent following the publication of several important works on the topic, including those of Spolsky and Cooper (1991), Landry and Bourhis (1997), Gorter (2006), Backhaus (2007), Shohamy and Gorter (2009), Jaworski and Thurlow (2010), Shohamy et al. (2010), and Gorter et al. (2012). The various studies mentioned above focused on public places and investigated various aspects of multilingualism such as presence, representation, visual positioning of different languages, and interpretations of languages as displayed on city walls. However, less attention has been devoted to institutions, including educational ones. As Gorter and Cenoz $(2015,151)$

(c) The Author(s). 2018 Open Access This article is distributed under the terms of the Creative Commons Attribution 4.0 International License (http://creativecommons.org/licenses/by/4.0/), which permits unrestricted use, distribution, and reproduction in any medium, provided you give appropriate credit to the original author(s) and the source, provide a link to the Creative Commons license, and indicate if changes were made. 
explain, "...investigations of institutional contexts, such as government buildings, libraries, museums, hospitals, laboratories, universities or schools, are a possible future direction in linguistic landscape studies." Shohamy and Waksman (2009) illustrate that education is one of the promising settings for the study of linguistic landscapes, contending that the employment of the linguistic landscape constitutes "a powerful tool for education, meaningful language learning, [and] towards activism" (p. 326).

This article examines the schoolscapes in Palestinian schools in Israel, where Arabic is the language of instruction and both Hebrew and English are taught as additional subjects. Given the conflict-ridden nature of the Israeli reality, the article explores the interesting and unique sociolinguistic context of these schools. At the core of this study are the language ideologies which are outlined in more detail below.

Before presenting the details of this study, the relevant studies on the schoolscapes and language ideologies are surveyed, followed by a brief description of the language education policies in Israel and the Palestinian repertoire.

\section{Schoolscapes and language ideologies}

The notion of linguistic landscape refers to the visibility of languages on objects that mark the public space in a given territory (Landry and Bourhis 1997). However, in the last five years, in the school context, some researchers started using the term schoolscape instead of linguistic landscape (e.g. Brown 2012; Szabó 2015; Biro 2016; Laihonen and Tódor 2017). Brown $(2012,282)$ defines schoolscape as "the school-based environment where place and text, both written (graphic) and oral, constitute, reproduce, and transform language ideologies." The notion of schoolscape reflects the different contexts and uniqueness of educational settings, focusing on texts, language awareness, and language education.

Besides, through examples from various languages, schoolscapes offer a fertile field for exploring the visual displays of the hidden curriculum with regard to language ideologies in education (e.g., Johnson 1980; Shohamy 2006; Aronin and Olaoire 2012; Brown 2012). In addition, schoolscapes can be employed in order to legitimize certain language ideologies. Accordingly, a schoolscape can be considered a branch of linguistic landscape, focusing on educational contexts.

As to language ideologies, Myhill (1999) has identified two ecologically based ideologies - the first associates language with individual identity while the second connects language to a specific territory. Heller (2003) has identified a third ideology which links language with the economy. The connection between language and economy is understood to be related to the effects of globalization and 'high' modernity (Giddens 1991).

As Biro $(2016,110)$ explains, "Language ideologies within the discussion of linguistic landscapes refers to a set of shared attitudes and beliefs of the given community about language or languages." Leeman and Modan (2009) view the linguistic landscape as ideologically charged and socially constructed representations of linguistic landscape search. As Moriarty $(2012,74)$ claims, "To this end, the linguistic landscape is seen not only to be reflective of language ideologies, but also a space where language ideologies can be indexed and performed, thus providing an apt tool for dealing with the multimodal nature of language ideologies." In the rest of this section, I will survey studies on schoolscapes in various educational contexts. 
In one study, Dagenais et al. (2009) requested that students in elementary schools in Vancouver and Montreal document the linguistic landscape of their urban setting by means of disposable cameras. The study revealed that the linguistic landscape could serve as a vehicle for teaching about language diversity and literacy practices from a critical perspective. The example of the politically and linguistically-loaded contexts of Quebec and Vancouver indicates that the linguistic landscape can function as a powerful educational instrument. Investigating the linguistic landscape of public space can help children understand the sociopolitical context in which they live (Dagenais et al. 2009).

Another similar study to the previous one, conducted by Clemente et al. (2012), examined the schoolscape in a Portuguese primary school. The researchers foregrounded the significance of understanding the attitudes toward diversity and the development of linguistic and cultural competences through education. The study demonstrated that children were able to recognize and read the schoolscape.

In a study by Hancock (2012), student teachers in Edinburgh, Scotland, were cast in the role of researchers of the linguistic landscape in order to encourage them to think about the multilingual community in which they lived. Their exploration of the linguistic landscape served as an awareness-raising technique aimed at preparing them for the reality of multilingual schools. Similarly, a study conducted by Sayer (2010) in Oaxaca, Mexico, had Mexican students assume the role of language investigators, with the schoolscape serving as a pedagogical tool in the EFL (English as a Foreign Language) classroom. The activities performed by the students linked the language in the streets to the language of the classroom. The purpose of the signs displayed on the streets, the intended viewers, and the diverse meanings of the English on the signs, were examined. This researcher claims that exposure to the schoolscape enables students to consider language in a creative and critical manner (Sayer 2010).

In another context, similar to that of Sayer's (2010) study, Rowland (2012) asked students in Japan to gather and analyze photographs of English displayed on public signs such as advertisements and road signs. The photographs were employed in classrooms where English was taught as a second language. Rowland's findings indicate that pedagogical schoolscape projects can be beneficial to EFL students chiefly in the development of students' symbolic competence and literacy skills (Rowland 2012).

Hanauer (2009) investigated the language employed in a high-school microbiology laboratory and determined that the schoolscape items found in the laboratory served two principal functions: (1) facilitating the students' knowledge acquisition, and (2) improving the procedural aspects of scientific research. He concluded that the linguistic landscape promoted both scientific and educational aims.

In contrast to other studies, Gorter and Cenoz (2015) examined the linguistic landscape existent within the educational context itself. The authors did not involve teachers or students directly, but rather studied the schoolscape inside multilingual schools in the Basque Country. They examined the use of three languages - Basque, Spanish, and English - by photographing the inside of classrooms, corridors, other rooms, and immediate surroundings including the schoolyard and the vestibule. They focused on the use of the three languages in the linguistic landscapes of the schools, the functions of the signs, the authors of the signs, and whether the signs were top-down (institutional) or bottomup (individual). Their findings indicated that the languages were used in different ways 
depending on the purpose, while their analysis revealed a variety of communicative intentions conveyed by the texts on the signs in the schools. Their study also demonstrated that signs could be monolingual or multilingual and could manifest different characteristics in the context of an educational space from those found in a public space. In another study, Gorter (2013) found that a multilingual schoolscape probably contributed to the multilingual competence of the students.

Several studies focus on schoolscapes in the context of language ideologies. Biro (2016), for instance, describes the visual manifestations of the linguistic landscape of Hungarian schools in Romania, revealing differences and similarities between the languages taught to minority children. The article also seeks to investigate the mutual efforts of the teachers and students to deal with the basic challenges of teaching and learning languages. Szabó (2015) investigates the schoolscapes of four schools in the city of Budapest, analyzing both the material environment and the metadiscourse through which such spaces are interpreted and regulated. Laihonen and Tódor (2017) explore the connections between a linguistic landscape and language ideologies in an elementary school in a village within the Hungarian region of Szeklerland in Romania. They analyze the school landscape "as a display or materialization of the 'hidden curriculum' regarding the construction of linguistic and cultural identities." (362).

The various studies reveal that the schoolscape can play important roles in educational contexts, leading to meaningful language learning, understanding of the sociopolitical context in which the students live, understanding of attitudes toward diversity, viewing usefulness as an awareness-raising technique, and exploring the visual displays of the hidden curriculum with regard to language ideologies in education. Examining schools from the linguistic landscape perspective can provide interesting insights into language education. As Szabó $(2015,111)$ contends, "studies of the signage in schools can lead to a better understanding of what goes on inside schools and, as such, contributes to education research."

The current study focuses on the Palestinian schoolscapes, in line with Gorter and Cenoz's study (2015), aiming at exploring the interesting and unique sociolinguistic contexts existing inside Palestinian schools in Israel.

\section{Language education policies in Israel and the Palestinian repertoire}

The government of the British Mandate $^{1}$ recognized three official languages in Palestine: English, Arabic, and Hebrew, in that order. After the establishment of the State of Israel, English was eliminated as an official language, and Hebrew and Arabic were retained as the official languages of the State (Saban and Amara 2002; Yitzhaki 2008; Pinto 2009; Mendel et al. 2016).

During the British Mandate, the Palestinian community and Jewish colonies were expected to run their own education systems. Most Palestinian schools used Arabic, and most Jewish schools taught in Hebrew. Some Arabic was taught in Jewish schools. English was used as a language of instruction in the high schools of the Palestinian and Jewish communities. However, Hebrew was not taught in Palestinian schools (Spolsky and Shohamy 1999; Amara and Mar'i 2002).

Today, generally speaking, Jewish and Palestinian students in Israel study in separate schools. Hebrew is the language of instruction in Jewish schools (except in some ultra- 
Orthodox schools, where Yiddish or other languages are used). Arabic is the language of instruction in Palestinian schools. Hebrew is studied as a second language by all the Palestinian students from the second grade on, or even earlier. ${ }^{2}$ Arabic is studied by tens of thousands of Hebrew speakers, mostly in junior high school (Landau-Tasseron et al. 2012). English is studied as a foreign language by both Jews and Palestinians (Amara and Mar'i 2002; Amara 2014, 2015).

The linguistic repertoire of Palestinian citizens in Israel is complex and diverse. Arabic is the language of personal, cultural, and national identity. Hebrew is important for social mobility, higher education, and shared citizenship. English, as a global language, is a window to the wider world (Amara 2014).

For most Palestinians in Israel, Hebrew is the most important second language, even more important than English, and, at times and in some domains, even more important than Arabic (Amara and Mari 2002; Shohamy and Donitsa-Schmidt 1998). English is relegated to the position of secondary preference after Hebrew. Palestinian students must first contend with their own Arabic mother tongue, which is characterized by an immense difference between the spoken and the written language. They must then become familiar with Hebrew, which is indispensable to them in daily life. Only after mastering these two languages do they focus on English - a language whose study is teacher-centered and frontal for the most part, and spoken by students only infrequently.

As regards language education, the Ministry of Education has adopted a double policy toward the Arabs: for Arabic as a mother tongue and for Hebrew for Arabic speakers. The curricula are distinct from those for Hebrew as a mother tongue and Arabic for speakers of Hebrew, but for English and French as a second or foreign language, the curriculum is the same for both the Arabic and the Hebrew sectors. An obvious effect of this is to use the language curricula in the Arab-Palestinian society to strengthen Israelization and to inhibit Arab and Palestinian nationalism (see Al-Haj 1996; Amara and Mar'i 2002). Mar'i (1978) defined Arab education in Israel as a field of battle between the Jewish authority and the Arab community. This battle is reflected in the teaching of the two languages, Arabic and Hebrew. The aim of the Hebrew teaching is to expose the Arab student to Hebrew culture and its past and present values; and the teaching of Arabic attempts to weaken the students' emotional and national ties with the Arab nation.

\section{Research questions}

The current study investigates the schoolscapes in six Palestinian high schools located in three towns in the Little Triangle ${ }^{3}$ in Israel: two in the North of the Triangle, two in the middle, and two in the south, providing a fair coverage of the investigated region. High schools were selected because their students have already studied Hebrew and English for a number of years and have acquired some functional abilities in the two languages, unlike elementary and junior high-school students, whose knowledge of the two languages is still basic. In this study, the distribution of the languages in the schoolscapes was explored by examining the functions of signs, distinguishing between the informative and the symbolic, according to the work of Gorter and Cenoz (2015) as inspired by the pioneering work of Landry and Bourhis (1997), determining the authorship of signs, and focusing on top-down vs. bottom-up signs. 
More specifically, the following questions are addressed:

1- What are the languages used in Palestinians schools? And how are they distributed on signs?

2- What functions do the signs have? And which languages are used for different functions?

3- Who are the authors of the signs (top-down versus bottom-up signs)? And are there differences in the use of the languages according to authors?

4- How do Palestinian schoolscapes compare to the general Palestinian linguistic landscape (GPLL) in terms of languages used?

\section{Methods}

Data were collected from six high schools in three towns in the Little Triangle during visits paid to the schools between April and June 2016. Photographs of the exterior of each school were taken, including the front of the school, with its name and schoolyard, and interior shots of the classrooms, libraries, and corridors. A total of 1216 photographs of signs were taken and analyzed. In addition, the 'tourist guide technique', developed by Szabó (2015), was applied. The above-mentioned researcher explains that according to this method, the researcher acts as a tourist guided by teachers. The teachers comment on the choice of language, symbols, and displays on the walls during their school tour and answer the researcher's questions. Thus, the researcher and the interviewee co-experience the space to be investigated.

I employed the tourist guide technique while taking pictures of signs in the school buildings. The principals of the six schools accompanied me, guided me through the corridors, classrooms, and other public spaces, and responded to my questions.

\section{Distribution of languages on signs}

Arabic, Hebrew, and English were all taught in the six schools in this study. The manner in which these three languages were displayed in the linguistic landscapes of the schools was examined. First, the number of languages used on the signs was determined prior to looking at which languages appeared on them.

The results show that most of the signs, $79 \%$, were monolingual. The bilingual signs comprised $20 \%$ of the total number of signs, while the trilingual signs represented the lowest percentage of signs, namely, $1 \%$.

The results of the study reveal that the characteristics of the signs displayed in the schools differed from those displayed in public spaces in the general Palestinian linguistic landscape (GPLL), such as road signs, names of sites, streets, buildings, places and institutions as well as advertising billboards, commercial shop signs and even personal visiting cards. Whereas in the schools, $79 \%$ of the signs were monolingual, GPLL in Israel, only $45 \%$ of the signs were monolingual (Amara 2010; Ben-Rafael et al. 2006). In addition, in the GPLL, 43.5\% of the signs were bilingual, as opposed to $20 \%$ in the schools. The GPLL also had a significantly higher percentage of trilingual signs - $11 \%$ - than the schools, which had only $1 \%$.

With regard to the languages used on the signs, Fig. 1 shows that Arabic was the most ubiquitous language in schools, appearing as the sole language on the highest percentage of signs $-51 \%$. In total, Arabic appeared on two-thirds (66\%) of the signs. Hebrew as the 


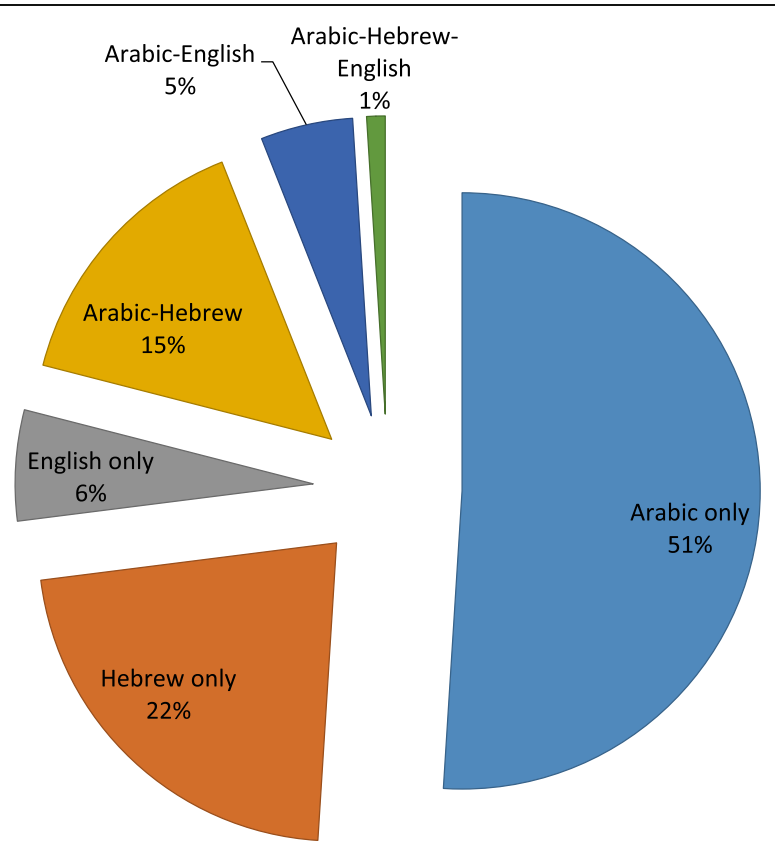

Fig. 1 The Language used on signs

only language appeared on more than one-fifth of the signs. Altogether, Hebrew appeared on more than one-third, or 37\%, of the signs. The representation of English was in third place, lagging far behind the two other languages, appearing on only $6 \%$ of the signs as the sole language, and with one or both of the other languages on $6 \%$ of all signs.

Figures 2, 3, 4, 5, 6 and 7 below provide examples of different patterns found in the schoolscapes, illustrating the different languages used on signs.

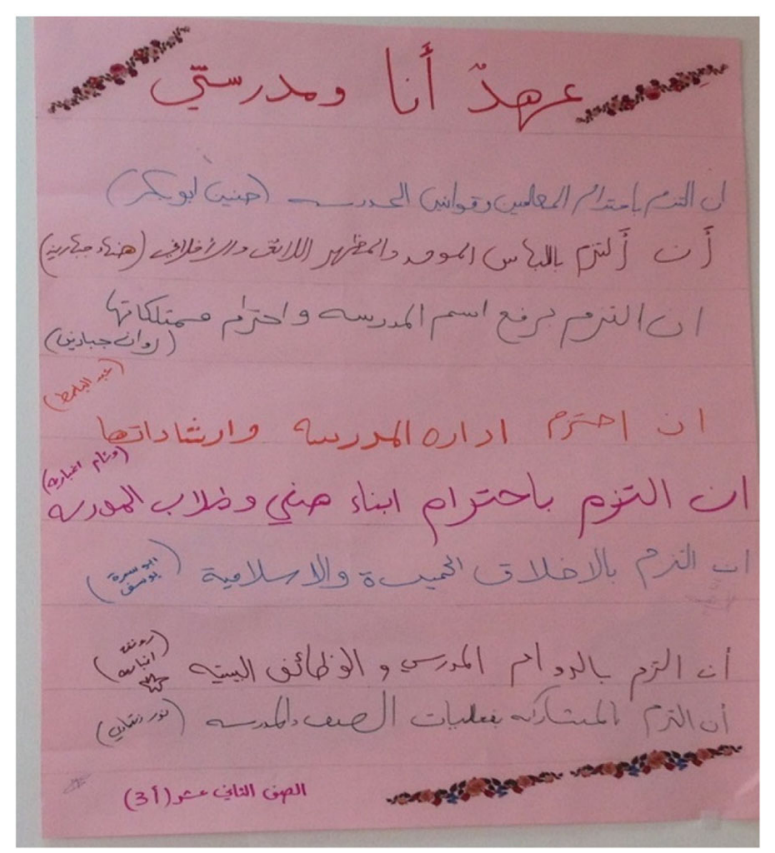

Fig. 2 Arabic-only schoolscape item 


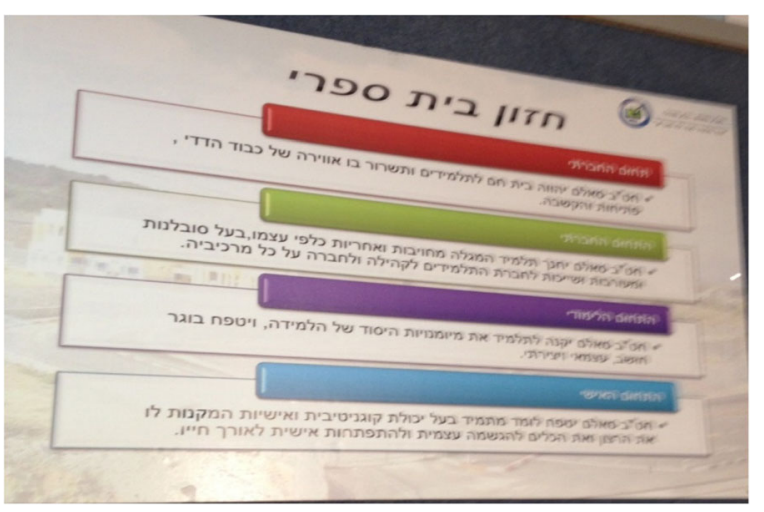

Fig. 3 Hebrew-only schoolscape item

This type of Arabic-only sign is widely used in the various school settings - classrooms, library, teachers' room - and is evident in handwritten and printed signs. Figure 2, which was found in a classroom, was written by one of the students. As explained by principal B, "The purpose of writing such a sign is to express commitment to the values of the school - for instance, to safeguard school property and to resolve problems with other classmates peacefully." He added, "The commitment to the school values is extremely important in order to strengthen belonging and loyalty."

Figure 3 represents a Hebrew-only sign. This type of sign, which is also widely used, occupies the second place after the Arabic-only signs, and is used and seen in various settings in the school. This printed sign describes the school vision. When principal D was asked why the sign was only in Hebrew, she replied, "It is directed at Jewish visitors, be they academics or Ministry of Education officials who visit the school occasionally."

English-only signs are not widely used in the investigated schools, and their use lags far behind that of both Arabic-only and Hebrew-only signs. They are found mostly in the

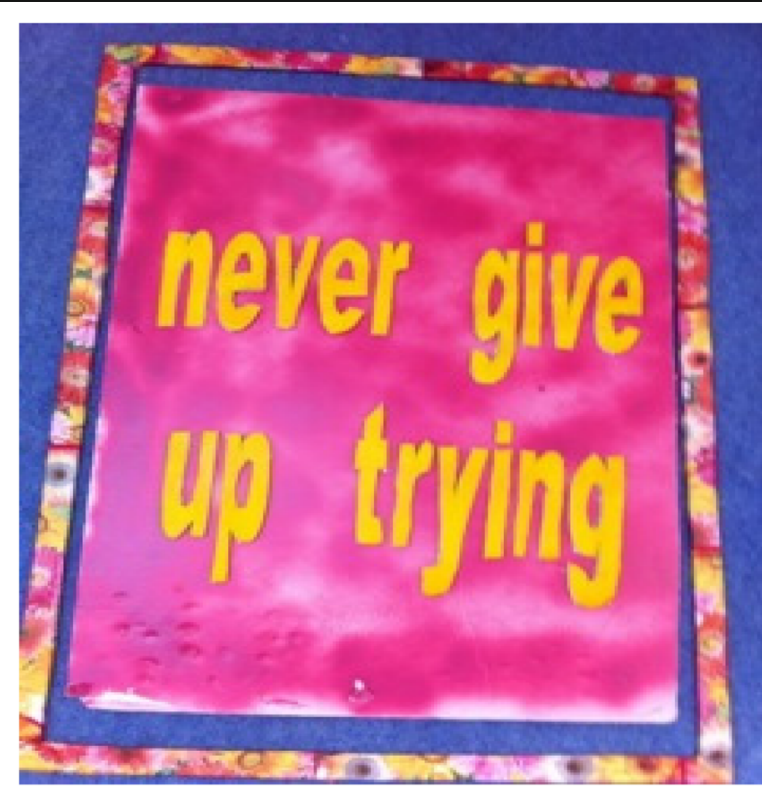

Fig. 4 English-only schoolscape item 


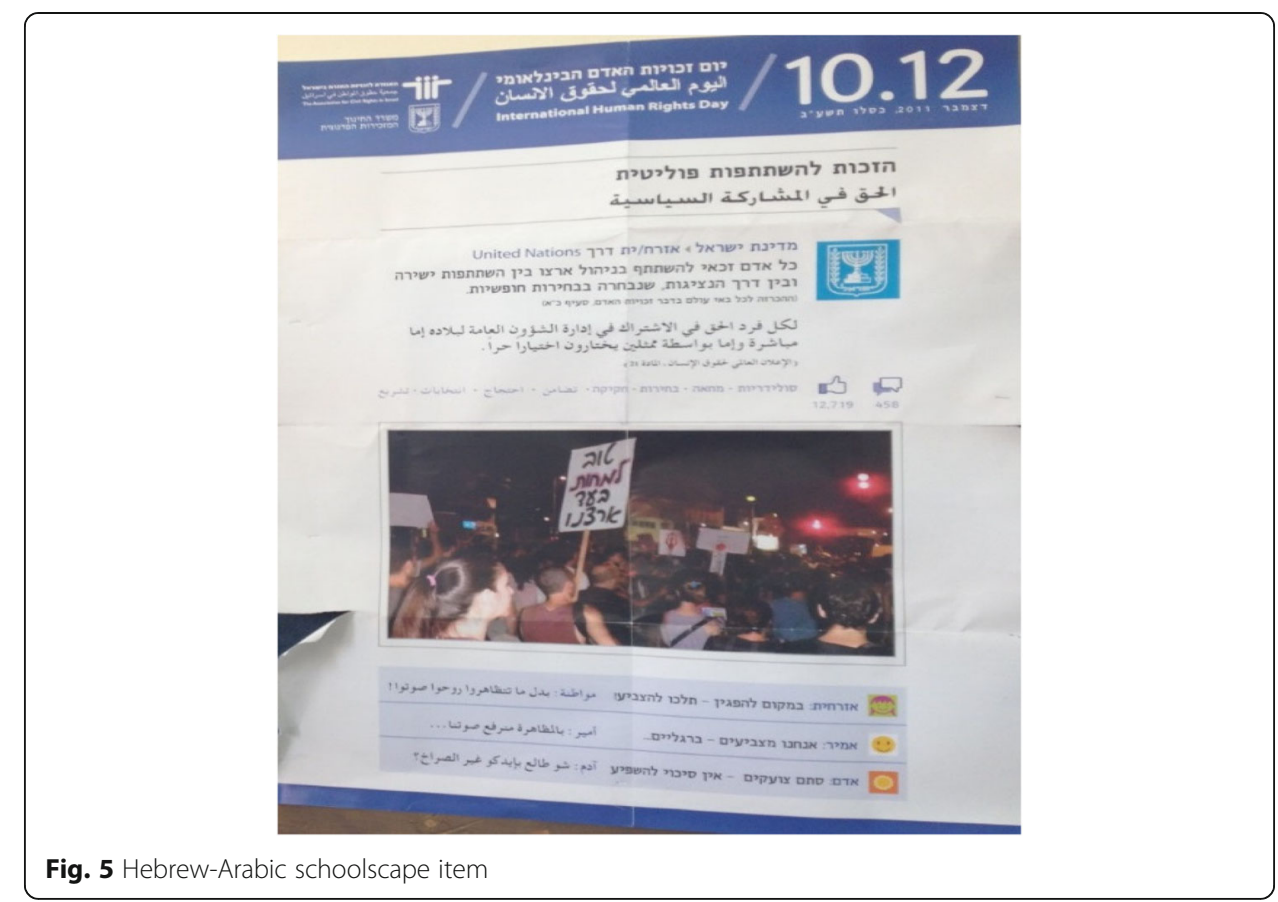

classrooms and are prepared mainly by students. Figure 4, which extolls the virtue of perseverance, was taken from a classroom. When principal $\mathrm{C}$ was asked about writing such a sign, which expresses an important school value, only in English, he responded, "It is important that students practice their English knowledge on the school walls, reflecting the multilingual nature of teaching three languages in our schools. Besides, it is important to express values in various languages. School is about imparting values and internalizing them."

Bilingual Hebrew-Arabic signs are widely used in various school settings. Figure 5 deals with the right to participate in political events. When principal A was asked why it was written in two languages, she replied, "It was sent to the schools by the Ministry of Education's Pedagogical Secretary on Human Rights Day." Principal C explained that "very often bilingual signs at our school are in Arabic and Hebrew, similar to other Arab schools in Israel. It is natural, considering that Hebrew is an official language, and the language of the state."

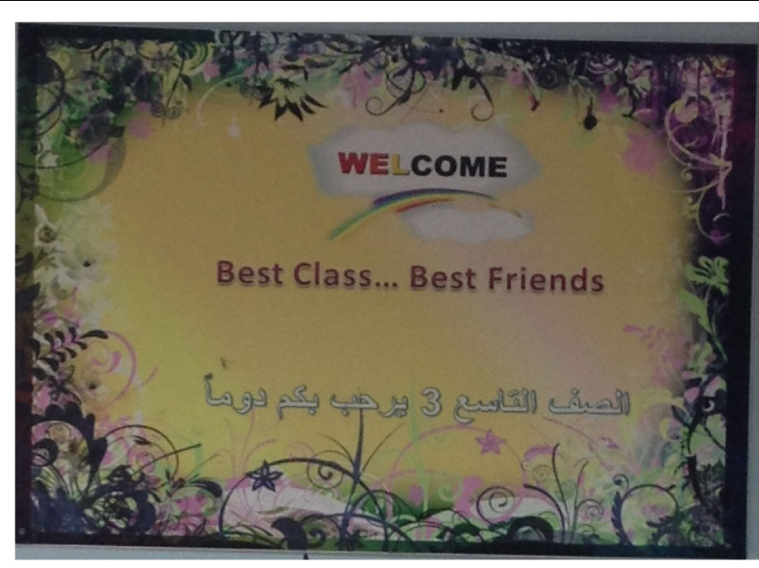

Fig. 6 Arabic-English schoolscape item 


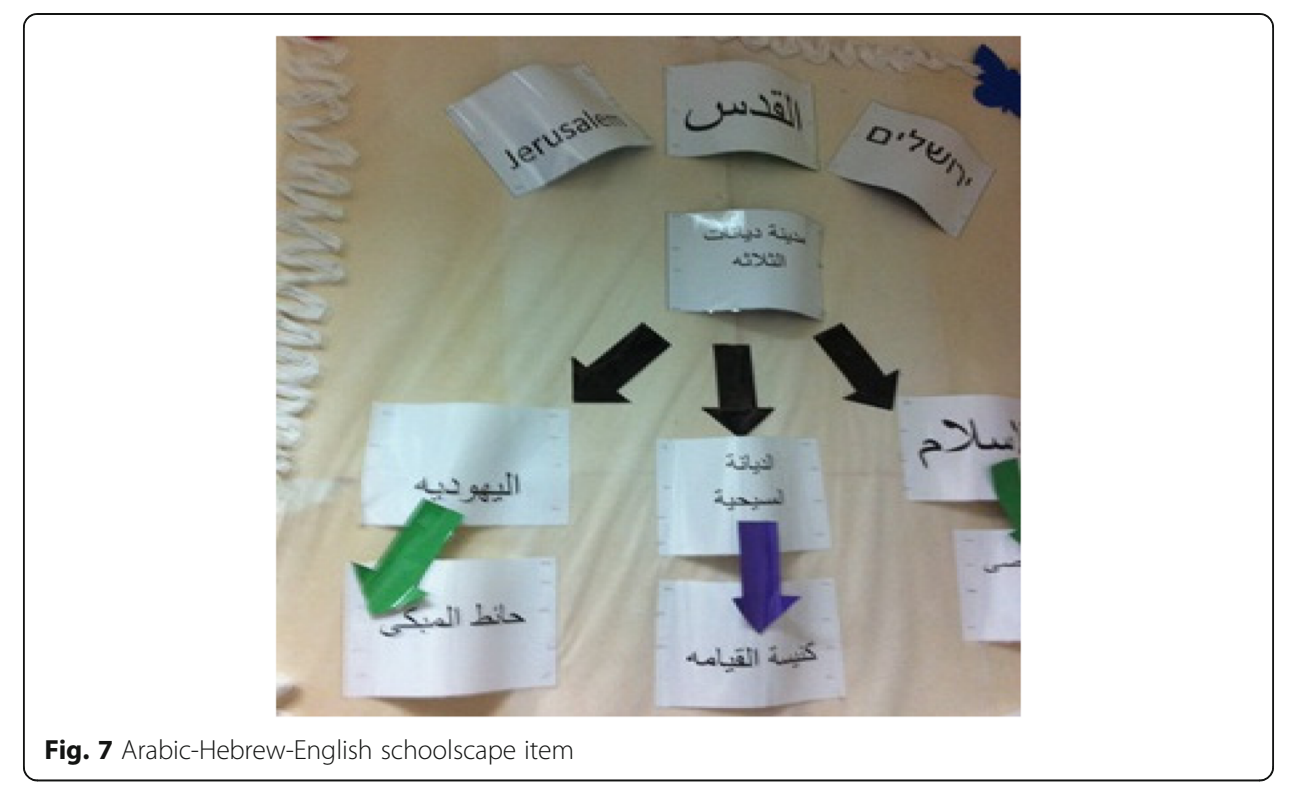

Arabic-English signs are used only in the classrooms. The sign in Fig. 6, which was prepared by the students, contains a message of improving the image of the class and reinforcing friendship. As principal C explained, "The Arabic on the sign is a translation of the word "Welcome" in English. English may have been used here because it is believed to be a prestigious language. Images are also well-received in English."

Trilingual Arabic-Hebrew-English signs are rarely used; they are seen only in educational contexts in classrooms. At the top of the sign shown in Fig. 7, the word Jerusalem is written in the original three languages rather than in the form of Arabic transliterations. Below the three versions of the name Jerusalem, there is a rubric whose Arabic text means "the city of the three religions". Beneath it, the sites that are sacred to the various religions are mentioned. As principal A commented, "Values related to peace and religious tolerance are important to us. Our students are encouraged to write about them in various languages."

\section{Authorship of signs: top-down vs. bottom-up}

As Ben-Rafael et al. (2006) have demonstrated, the distinction between top-down and bottom-up is useful. In the schools, there are various sign-writers: students, teachers, and outside sources, chiefly the Ministry of Education and municipalities. In the case of school signage, students represent the bottom-up or individual perspective, while the other authors or sources represent the top-down or institutional perspective. The various authors have different goals and functions that affect their decision to write in one language or another.

As can be seen in Fig. 8 below, the highest percentage of top-down signs are bilingual Arabic-Hebrew signs (34\%). In addition, the percentage of monolingual Hebrew signs (29\%) exceeds that of the monolingual Arabic signs (25\%). Moreover, English does not appear as the sole language at all on the top-down signs. On the other hand, monolingual Arabic signs account for the highest percentage of bottom-up signs. Monolingual English and monolingual Hebrew signs are also present (15\% and 11\% respectively).

Signs provided by the Ministry of Education, classified as top-down, are written mainly in Hebrew. In a few cases, when the author was an Arab, and the message was 


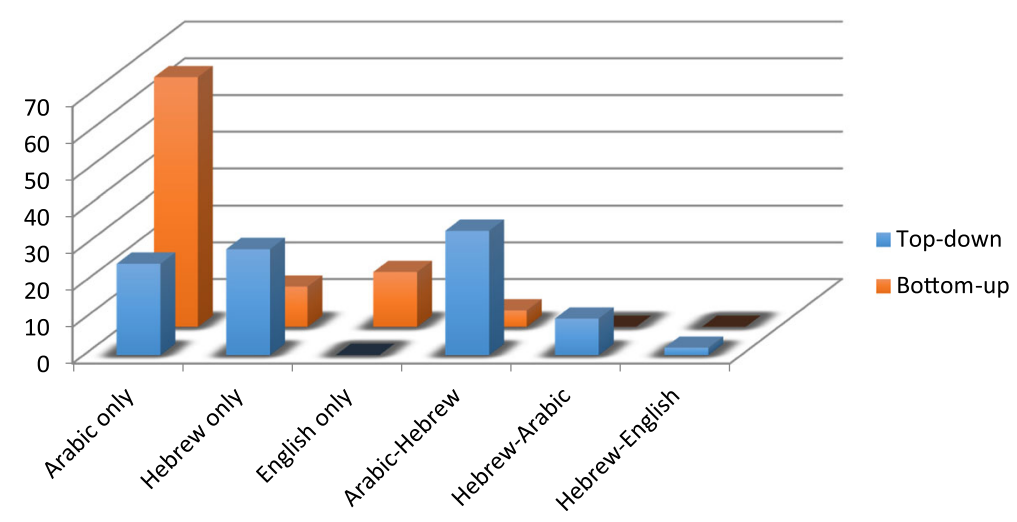

Fig. 8 Top-down vs. bottom-up schoolscape (\%)

directed at an Arab audience, the sign was written in Arabic. Another authority, or topdown actor, is the municipality. Signs provided by the municipality were bilingual (Arabic-Hebrew). Regarding the school principal as another authority making top-down decisions about many signs inside the school, various patterns were detected: Arabic-only when the message was directed at students; Hebrew-Arabic when the message was directed at visitors as well as students; and sometimes Hebrew-only when it was directed at teachers. The bottom-up signage, written by students, was mainly in Arabic only.

Again, when we compare the results of this study with the GPLL regarding top-down versus bottom-up items, a different picture is revealed (Ben-Rafael et al. 2006). Whereas in the GPLL in Israel, Hebrew-only is more significantly used in bottom-up than in top-down, $(40.7 \%$ vs. $3.9 \%)$, the opposite is true in the six studied schools: $29 \%$ in top-down vs. $11 \%$ in bottom-up. This is also the case in the Hebrew-Arabic bilingual signs. As regards the bottom-up signs, the GPLL had a significantly higher percentage of such signs in Hebrew-Arabic (37\% vs. 11\%) in schools. Trilingual Hebrew-ArabicEnglish signs were widely used in the GPLL (top-down 36.8\% and bottom-up 22.2\%), whereas in schools they were only used in bottom-up with a mere $1 \%$.

\section{Informative vs. symbolic functions}

In accordance with Landry and Bourhis (1997), a differentiation was made between informative and symbolic functions. However, the distinction between the two functions was not clear enough in Landry and Bourhis. A finer and more useful distinction is drawn by Gorter and Cenoz $(2015,155)$, who differentiated among nine different functions:

1. Teaching of language and subject content [informative]

2. Classroom management [informative]

3. School management [informative]

4. Teaching values [symbolic]

5. Development of intercultural awareness [symbolic]

6. Promotion of the Basque language [symbolic]

7. Announcement of collective events [informative and symbolic]

8. Provision of commercial information [informative and symbolic]

9. Decoration [informative and symbolic] 
In this study, I identified eight functions: three informative functions (teaching content, classroom management, and school management), three symbolic functions (teaching values, development of intercultural awareness, and the promotion of the Arabic language), and two informative and symbolic functions (announcing collective events and decoration). The overwhelming majority of the signs, $85 \%$, were informative, $10 \%$ were symbolic, and $5 \%$ were informative and symbolic simultaneously. Gorter and Cenoz (2015) report the same functions in their study, although no quantitative measure was provided.

As concerns the informative functions, the teaching content signs are displayed mainly on the walls of the classrooms. They are used as learning materials or as learning aids. Regarding classroom management signs, they inform students of the expected behavior at school in general and toward their classmates. According to Gorter and Cenoz (ibid., 156), these are 'rules of etiquette'. Both the teaching content and class management functions are mainly directed at students. School management topics are addressed to students, teachers, and even visitors, and are mainly concerned with directing people to the various locations in the school.

Regarding the symbolic signs, teaching values chiefly address the students, seeking to make them aware of values that are important to them or enabling the teachers to raise students' awareness of important school and social values. Another symbolic function is the development of intercultural awareness whose purpose is to make students aware of other cultures. The third symbolic function is the promotion of the Arabic language. The latter is extremely important for both teachers and students both as a marker of identity and as a language challenged by other foreign languages, mainly Hebrew and English. Many schools hold an annual "Arabic Language Week". During that week, various activities focusing on the Arabic language are conducted, with an evident emphasis on the symbolic aspect of the language.

Signs categorized as both informative and symbolic announced collective events, such as Arab and Islamic occasions, and included decorations with Arabic calligraphy.

Figures 9, 10, 11 and 12 below provide examples of informative and symbolic signs:

Figure 9 represents an informative sign. Such signs are used in various linguistic patterns, and Arabic-Hebrew signs, especially outside the classroom, are prevalent. Figure 9 furnishes directions to the school management. Principal A explained that "it is taken

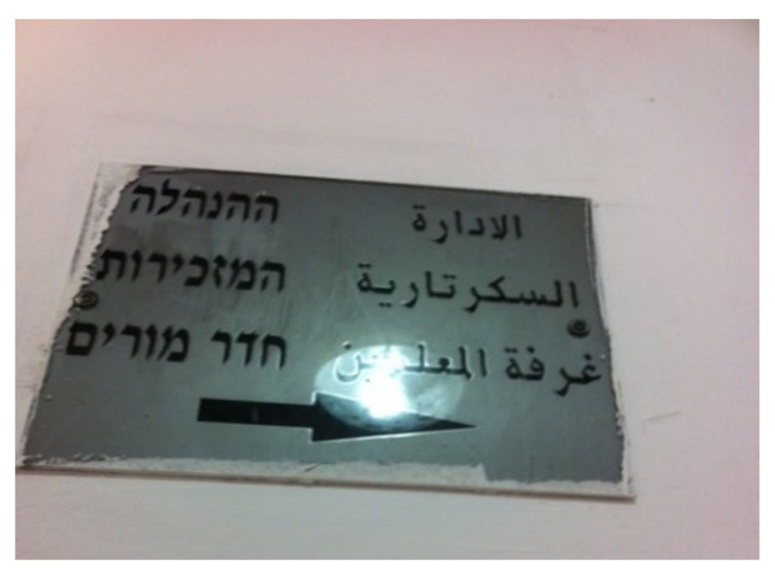

Fig. 9 An infromative sign concerning the location of the school management 


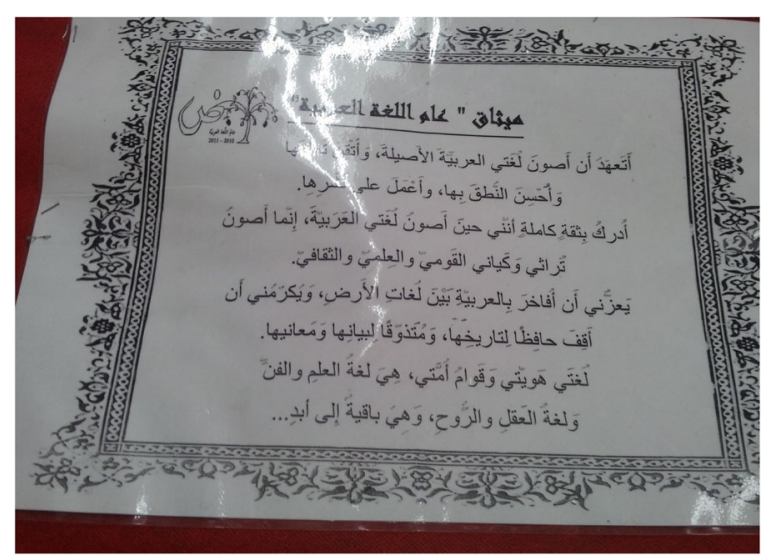

Fig. 10 A symbolic sign concerning the Arabic language

for granted that such signs should be bilingual, Arabic-Hebrew, because visitors to schools are both Arabic and Hebrew speakers."

This sign (Fig. 10) was prepared during the Arabic Language Week. Titled "The Covenant of the Arabic Language", the left side of the sign features the letter /d /, which symbolizes the Arabic language. Arabs believe that this letter exists only in Arabic. The entire sign focuses on protecting Standard Arabic. The first two lines read as follows: "I promise to preserve my authentic Arabic language, command it fully, pronounce it properly, and work to spread it."

Figure 11, which was found in a classroom, is a symbolic sign that describes peaceful living in Tibet. Its purpose is to develop cultural awareness among students. Signs of this type occur mainly in Arabic. As principal A commented on the picture, "We anticipate the day when we will live peacefully in this conflicted region. Our students need to be aware of other cases in the world, and believe that it is possible to live in peace."

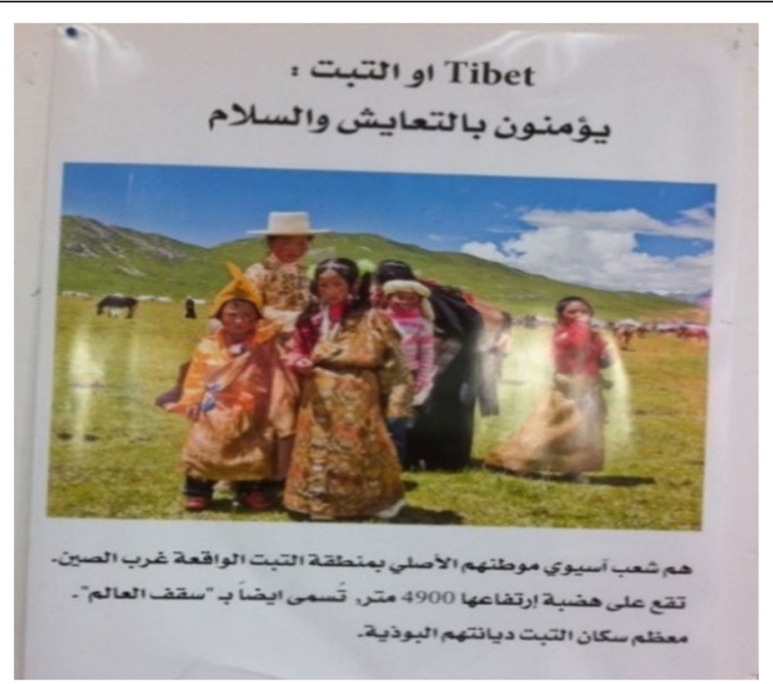

Fig. 11 A symbolic sign- developing intercultural awareness 


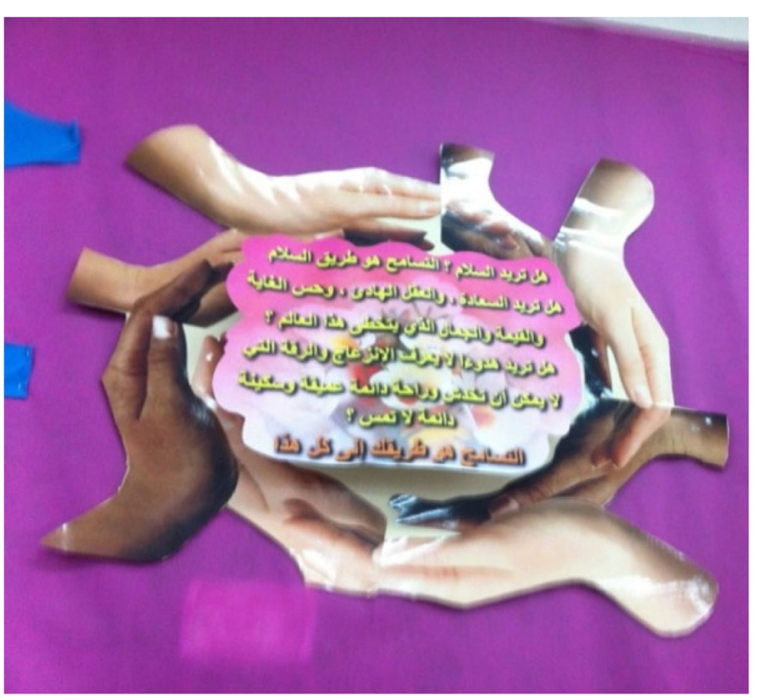

Fig. 12 An example of a symbolic sign on teaching values

Figure 12 delivers a message about the value of tolerance. It explains the meaning of tolerance and how to promote it as a way of living. These types of signs are written mainly in Arabic. When principal B was asked why the value of tolerance appears frequently at school and is written mainly in Arabic, his response was, "As you know, our Arab society is becoming more violent. We work on this value in various ways and devote particular attention to it, in the hopes of educating a generation that believes in peaceful ways of conflict resolution."

\section{Discussion and conclusions}

This paper has explored the display of the various languages employed in six Palestinian schoolscapes in Israel. The findings reveal that Arabic, Hebrew, and English are used in the examined Palestinian schoolscapes in Israel. Arabic is the most ubiquitous language. The Arabic language was placed in what Scollon and Scollon (2003) called the preferred position. The presence of Hebrew is also significant. Hebrew as a national and official language in Israel, and vital language in the Israeli Palestinian linguistic repertoire is widely reflected in the schoolscapes. English lags far behind that of the two other languages. English is almost invisible in the schoolscapes despite the fact that it is a valuable language for the Palestinian students.

The authorship of signs, distinguishing between top-down and bottom-up signs, reveals significant differences. The majority of top-down signs were either bilingual (Arabic-Hebrew) or monolingual (Hebrew). There were far more top-down monolingual Hebrew signs than top-down monolingual Arabic signs. Thus, the top-down public language displays in the school clearly support the Hebrew language, while bottomup displays demonstrate the dominance of Arabic in the signs. In addition, English did not feature at all on the top-down signs. Most of the bottom-up signs appeared in monolingual Arabic. That said, monolingual English and monolingual Hebrew signs also existed. Furthermore, the number of bottom-up monolingual English signs exceeded that of bottom-up monolingual Hebrew signs. Hebrew is still relatively a 
marginal language in bottom-up signs in schools, unlike bottom-up signs in Palestinian localities, where Hebrew and Arabic-Hebrew signs feature prominently.

Another examined dimension of the schoolscape is function. Gorter and $\mathrm{Cenoz}$ (2015) classified school signs according to three major functions: (1) informative, (2) symbolic, and (3) both informative and symbolic. Our findings demonstrate that the function of the majority of the signs was informative, and included teaching content, classroom management, and school management. The function of only a few signs was symbolic or both informative and symbolic, and those primarily involved teaching values and developing intercultural awareness. One possible explanation for the presence of a greater number of informative signs than other types of signs might be that in learning contexts, the target audiences are mainly students, with the result that most of the signs are designed to disseminate teaching content. These results tally with those of Gorter and Cenoz (2015), who noted that symbolic signs appear less frequently than informative signs.

What do we learn from this study? The schoolscapes in this study served as a social space for the public display of local identity. It is evident from both the quantitative results and the feedback of the principals in the guided tour that reinforcing the Arabic language is a major goal of the schools. Language ideologies are clearly reflected in the schoolscapes.

The schoolscapes are characterized by the unequivocable dominance of standard Arabic, while the local Palestinian dialect is excluded from the schoolscapes of all the schools. As principal C said, "The local Palestinian dialect is the dominant variety in daily life, and is present in the smartphones and the new technologies. We are the last shield for protecting Standard Arabic from getting lost." As Szabó (2015, p. 24) explains, "Schoolscapes are determined not only by laws and regulations, but by the visual practices of the given institutions as well. Inscriptions and cultural symbols placed on the façade and the wall of the school building are tools for orienting the choice between various cultural and linguistic ideologies."

Biro (2016) contends that schoolscapes can be employed in order to legitimize certain language ideologies. The extensive use of Arabic in the Palestinian schoolscapes serves to ascertain its importance for their Arab-Palestinian identity. As principal F claimed, "Arabic is the language of our national and cultural identity. School is the place where it needs to be promoted and conveyed to the next generation. The outside sociolinguistic world, mainly impacted by Hebrew, negatively influences Arabic. It is our duty to preserve Arabic. We exploit the various occasions in order to reinforce the Arabic language inside and outside the classroom environment." Other principals expressed the same idea during the guided tour, stressing that one of their essential roles was to enhance the Arabic language as a cultural and national identity.

This is possibly the case due to the conflict-ridden Israeli reality, in which PalestinianJewish relationships in Israel are characterized by constant tension. In this reality, the Palestinian citizens of Israel emphasize their identity and preserve it in various ways (see Al-Haj 1993; Rouhana 1993; Riter 1995; Amara and Kabaha 1996). They consider Arabic to be an authentic language and a marker of their identity and traditions.

The findings show that the schoolscapes are largely monolingual (Arabic-only, or Hebrew-only) or bilingual (Arabic-Hebrew) although the students are multilingual, since they learn three languages at school, Arabic, Hebrew and English. However, 
English barely features in these schools. Its sparse presence is in the bottom-up signage, used mainly for learning activities.

Hebrew is widely used in the schoolscapes. However, it is mainly present in the topdown signage, through communications sent in Hebrew to schools from the Ministry of Education. Although Arabic is an official language in Israel, everyday communication among all the departments in the Palestinian Arab education system in Israel and the schools is done in Hebrew. Through this language educational policy, the purpose is to strengthen the Hebrew language and weaken the use of the Arabic language in the school scene (Amara 2018).

Schoolscapes offer a fertile field for exploring the visual displays of languages in educational contexts The salience of the Arabic language in schoolscapes serves to promote it as a marker of Arab-Palestinian cultural and national identity, possibly as a reaction to the policies of the Israeli Ministry of Education, which attempts to denationalize Arabic language education (stripping Arabic language teaching of its national identity and consciousness) and Hebraize larger sections of the Arab society through the excessive use of Jewish culture and literature in teaching Hebrew of Arab society via the excessive use of Jewish culture and literature in teaching Hebrew (Al-Haj 1996; Amara and Mar'i 2002).

\section{Endnotes}

${ }^{1}$ Following the end of World War I, Palestine was placed for an interim period under a British Mandate, which formally began in 1922. The British Mandate was a turbulent period marked by continual violence between Arabs and Jews, both of whom opposed it. The Mandate over Palestine ended on May 15, 1948 and the establishment of Israel ensued (see Amara 1999, 21).

${ }^{2}$ In 2015, the Ministry of Education launched a new program aimed at improving the oral Hebrew proficiency of Arabic-speaking children from the kindergarten stage, with the emphasis on improving the pupils' competence in Hebrew. Minister of Education Naftali Bennett explained that "the decision to bring forward the Hebrew language study to preschools in the Arab sector stems from thinking about the children's future. We believe that as students from the Arab sector attain a better command of the Hebrew language, their integration into the economy, employment, and society will be better and easier" (Scoop 2015. http://www.haaretz.co.il/news/education/1.2707551).

${ }^{3}$ The Little Triangle, located between the West Bank of the Jordan River and the Israel's coastal region, is a geographic term (as well as a reality) that was coined only after the establishment of the State of Israel in 1948. Upon implementation of the ceasefire imposed by the Rhodes Agreement, the area was handed over to Israel by Jordan. Its borders were dictated by military events and political agreements (Amara 1999, 250).

Author's contribution

The author read and approved the final manuscript 
Received: 29 November 2017 Accepted: 19 April 2018

Published online: 03 May 2018

\section{References}

Al-Haj, M. (1993). The impact of the intifada on the orientation of the Arabs in Israel: The case of double periphery. In A. Cohen \& G. Wolsfeld (Eds.), Framing the intifada: Media and people (pp. 64-75). Norwood: Norwood Ablex Publishing Corporation.

Al-Haj, M. (1996). Education among the Arabs in Israel - Control and social change (in Hebrew). Jerusalem: Magnes Press, Hebrew University.

Amara, M. (1999). Politics and sociolinguistic reflexes: Palestinian border villages. Amsterdam: John Benjamins Co..

Amara, M. (2010). Arabic language in Israel: Contexts and challenges (in Arabic). Nazareth and Amman: Dar Al-Huda, Dirasat and Dar Al-Fiker.

Amara, M. (2014). Policy and teaching English to Palestinian students in Israel: An ecological perspective to language education policies. In V. Zentoz, Z. Jasone, \& D. Gorter (Eds.), Minority languages and multilingual education: Bridging the local and the global (pp. 105-118). Dordrecht, NY and London: Springer.

Amara, M. (2015). Hebraization in the Palestinian language landscape in Israel. In B. Spolsky, O. I. Lourie, \& M. Tannenbaum (Eds.), Challenges for language education and policy (pp. 182-194). NY: Routledge.

Amara, M. (2018). Arabic in Israel: Language, identity, and conflict. London and NY: Routledge.

Amara, M., \& Kabaha, S. (1996). Identity split: Political division and social reflexes in a divided village. Tamra: The Institute for Peace studies: Giv'at Haviva (In Hebrew).

Amara, M., \& Mar'i, A. (2002). Language education policy: The Arab minority in Israel. Dordrecht: Kluwer Academic.

Aronin, L., \& Olaoire, M. (2012). The material culture of multilingualism. In H. F. Marten, D. Gorter, \& L. van Mensel (Eds.), Minority languages in the linguistic landscape (pp. 229-318). New York: Palgrave Macmillan.

Backhaus, P. (2007). Linguistic landscape: A comparative study of urban multilingualism in Tokyo. Clevedon: Multilingual Matters.

Ben-Rafael, E., Shohamy, E., Amara, M. H., \& Trumper-Hecht, N. (2006). Linguistic landscape as symbolic construction of the public space: The case of Israel. International Journal of Multilingualism, 3(1), 7-30.

Biro, E. (2016). Leaning schoolscapes in a minority setting. Acta Universitatatis Sapientiae, Philologica, 8(2), 109-121.

Brown, K. D. (2012). The linguistic landscape of educational spaces: Language revitalization and schools in southeastern Estonia. In H. F. Marten, D. Gorter, \& L. van Mensel (Eds.), Minority languages in the linguistic landscape (pp. 281-298). New York: Palgrave Macmillan.

Clemente, M., Andrade, A. I., \& Martins, F. (2012). Learning to read the world, learning to look at the linguistic landscape: A primary school study. In C. Helot, M. Barni, R. Janssens, \& C. Bagna (Eds.), Linguistic landscapes, multilingualism, and social change (pp. 267-285). Frankfurt: Peter Lang.

Dagenais, D., Moore, D., Sabatier, C., Lamarre, P., \& Armand, F. (2009). Linguistic landscape and language awareness. In E. Shohamy \& D. Gorter (Eds.), Linguistic landscape: Expanding the scenery (pp. 253-269). New York: Routledge.

Giddens, A. (1991). Modernity and self-identity: Self and society in the late modern age. Cambridge: Polity Press.

Gorter, D. (2006). Introduction: The study of the linguistic landscape as a new approach to multilingualism. Journal of Multilingualism, 3(1), 1-6.

Gorter, D. (2013). Linguistic landscapes in a multilingual world. Annual Review of Applied Linguistics, 33, 190-212.

Gorter, D., \& Cenoz, J. (2015). Linguistic landscapes inside multilingual schools. In B. Spolsky, O. I. Lourie, \& M. Tannenbaum (Eds.), Challenges for language education and policy (pp. 151-169). NY: Routledge.

Gorter, D., Heiko, F., Marten, H. F., \& Mensel, L. V. (Eds.). (2012). Minority languages in the linguistic landscape. New York: Palgrave Macmillan.

Hanauer, D. I. (2009). Science and linguistic landscape: A genre analysis of representational wall space in a microbiology laboratory. In E. Shohamy \& D. Gorter (Eds.), Linguistic landscape: Expanding the scenery (pp. 287-301). New York: Routledge.

Hancock, A. (2012). Capturing the linguistic landscape of Edinburgh: A pedagogical tool to investigate student teachers' understandings of cultural and linguistic diversity. In C. Helot, M. Barni, R. Janssens, \& C. Bagna (Eds.), Linguistic landscapes, multilingualism, and social change (pp. 249-266). Frankfurt: Peter Lang.

Heller, M. (2003). Alternative ideologies of la francophonie. In R. Harris \& B. Rampton (Eds.), The language, ethnicity and race reader (pp. 225-242). London: Routledge.

Jaworski, A., \& Thurlow, C. (Eds.). (2010). Semiotic landscapes: Language, image, and space. London and New York: Continuum.

Johnson, N. B. (1980). The material culture of public schools: The symbolic integration of local schools and national culture. Anthropology and Education Quarterly, 11(3), 173-190.

Laihonen, P., \& Tódor, E. M. (2017). The changing schoolscape in a Szekler village in Romania: Signs of diversity in rehungarization. International Journal of Bilingual Education and Bilingualism, 20(3), 362-379.

Landau-Tasseron, E., Olshtain, E., Efrati, O., \& Milson, M. (2012). In G. Ron-Gillboa (Ed.), Teaching Arabic: Where do we go from here? Report from Symposia held by the expert committee on Arabic instruction in the Israeli Hebrew-language school system. Jerusalem: The Initiative for Applied Education Research the Israel Academy of Sciences and Humanities.

Landry, R., \& Bourhis, R. Y. (1997). Linguistic landscape and ethnolinguistic vitality: An empirical study. Journal of Language and Social Psychology, 16(1), 23-49.

Leeman, J., \& Modan, G. (2009). Commodified language in Chinatown: A contextualized approach to linguistic landscape. Journal of SocioLinguistics, 13(3), 332-362.

Mar'i, S. (1978). Arab education in Israel. Syracuse: Syracuse University Press.

Mendel, J., Yitzhaki, D., \& Pinto, M. (2016). Official but not recognized: The precarious status of the Arabic language in Israel and the need to redress this (in Hebrew). Giluy Da'at, 10, 17-45.

Moriarty, M. (2012). Lanquage ideological debates in the linguistic landscape of an Irish tourist town. In D. Gorter, H. F. Marten, \& L. V. Mensel (Eds.), Minority languages in the linguistic landscape (pp. 74-88). New York: Palgrave Macmillan. 
Myhill, J. (1999). Identity, territoriality and minority language survival. Journal of Multilingual and Multicultural Development, 20(1), 34-50.

Pinto, M. (2009). Who is afraid of language rights in Israel? In A. Sagi \& O. Nachtomy (Eds.), The multicultural challenge in Israel (pp. 26-51). Boston: Academic Studies Press.

Riter, Y. (1995). Between a Jewish state and a state of all its inhabitants: The status of the Arabs in Israel in an era of peace. Hamizrah Hahadash, 27, 45-60 (In Hebrew).

Rouhana, N. (1993). Accentuated identities in protracted conflict: The collective identity of the Palestinian citizens in Israel. Asian and African Studies, 27, 97-127.

Rowland, L. (2012). The pedagogical benefits of linguistic landscape project in Japan. International Journal of Bilingual Education and Bilingualism, 16(4), 494-505.

Saban, I., \& Amara, M. (2002). The status of Arabic in Israel: Reflections on the power of law to produce social change. Israel Law Review, 36(2), 5-39.

Sayer, P. (2010). Using the linguistic landscape as a pedagogical resource. ELT Journal, 64, 143-154.

Scollon, R., \& Scollon, S. (2003). Discourses in place: Language in the material world. London: Routledge.

Scoop, Y. 2015. Hebrew studies in the Arab education will start from kindergarten. Ha'aretz 13-8-2015 http://www. haaretz.co.il/news/education/1.2707551. (In Hebrew).

Shohamy, E. (2006). Lanquage policy: Hidden agendas and new approaches. London: Routledge.

Shohamy, E., Ben-Rafael, E., \& Barni, M. (Eds.). (2010). Linguistic landscape in the city. Bristol: Multilingual Matters.

Shohamy, E., \& Donitsa-Schmidt, S. (1998). Jews vs. Arabs: Language attitudes and stereotypes. Tel Aviv: The Tami Steinmetz center for peace research. Tel Aviv: Tel Aviv University.

Shohamy, E., \& Gorter, D. (Eds.). (2009). Linguistic landscape: Expanding the scenery. London: Routledge.

Shohamy, E., \& Waksman, S. (2009). Linguistic landscape as an ecological arena: Modalities, meaning, negotiations, education. In E. Shohamy \& D. Gorter (Eds.), Linguistic landscape: Expanding the scenery (pp. 313-331). New York: Routledge.

Spolsky, B., \& Cooper, R. L. (1991). The languages of Jerusalem. Oxford: Clarendon.

Spolsky, B., \& Shohamy, E. (1999). Languages of Israel: Policy, ideology and practice. Clevedon: Multilingual Matters.

Szabó, T. P. (2015). The management of diversity in schoolscapes: An analysis of Hungarian practices. Journal of Applied Language Studies, 9(1), 23-51.

Yitzhaki, D. (2008). Minority languages and language policy: The case of Arabic in Israel. Ramat-Gan: PhD Dissertation, Barllan University.

Submit your manuscript to a SpringerOpen ${ }^{\odot}$ journal and benefit from:

- Convenient online submission

- Rigorous peer review

Open access: articles freely available online

High visibility within the field

- Retaining the copyright to your article

Submit your next manuscript at $>$ springeropen.com 